\title{
All hands on deck: polycentric governance for climate change insurance
}

\author{
Connor P. Spreng ${ }^{1} \cdot$ Benjamin K. Sovacool $^{2}$. \\ Daniel Spreng ${ }^{3}$
}

Received: 8 November 2015 / Accepted: 17 August 2016 / Published online: 26 August 2016

C) The Author(s) 2016. This article is published with open access at Springerlink.com

\begin{abstract}
In this essay, we argue that it is possible to significantly complement and improve our collective response to climate change by harnessing the combined capacities of key actors across the public and private sector. We apply the concepts of liability, market mechanisms, preferential market access, and polycentric governance toward a new type of climate change insurance for $\mathrm{CO}_{2}$. The quest to apply insurance principles to climate change dates back multiple decades. But ideas for employing the industry's ability to help avoid or minimize and, if necessary, compensate for uncertain costs in the future at scale, across national boundaries, and as part of a broader regime, seem to be lacking. We propose an approach that complements and combines ongoing efforts within a polycentric governance structure to reduce $\mathrm{CO}_{2}$ emissions, increase resilience to and compensate damages from climate change on a global scale.
\end{abstract}

\section{Introduction}

Even as the seriousness of a changing climate is largely acknowledged, the existing responses to climate change are - collectively - falling short of achieving the desired degree of reductions in carbon dioxide $\left(\mathrm{CO}_{2}\right)$ emissions, the main cause of climate change.

Connor P. Spreng

cspreng@worldbank.org

Benjamin K. Sovacool

B.Sovacool@ sussex.ac.uk

Daniel Spreng

dspreng@ethz.ch

1 World Bank Group, Istanbul, Turkey

2 Sussex Energy Group, University of Sussex, Brighton, UK

3 Centre for Energy Policy and Economics, ETH Zurich, Zürich, Switzerland 
The proposal we outline here is based on the following hypothesis: it is possible to significantly complement and improve our collective response by building on capacities that different actors already have and combining ongoing efforts within a polycentric governance structure. The key element is the application of insurance principles to establish a global regime of manageable $\mathrm{CO}_{2}$ emissions.

Looking to the insurance industry for addressing climate change is not new, a quest that goes back at least 40 years (Munich Re 1973). Stephen Schneider (Schneider and KuntzDuriseti 2002), like others (Chichilnisky and Heal 1993; Shiller 2014), saw climate change to be an insurance problem. Schneider said "We buy fire insurance for a house and health insurance for our bodies. We need planetary sustainability insurance." (Nuzzo 2005). Allen (2003) wrote more than a decade ago that the question of insurance and liability for climate change may be the biggest question of all in climate policy and negotiations. The G7 meeting in 2015 called for insurance schemes to address climate change problems, as has the Conference of Parties (COP) of the United Nations Framework Convention on Climate Change (UNFCCC). COP19 established a committee, the Warsaw International Mechanism for Loss and Damage, to look into the matter (UNFCCC 2013) and COP21, with its Paris Agreement, encourages risk assessment and the incorporation of insurance solutions in managing climate change (UNFCCC 2015).

The insurance industry itself was active early on (Mills 2005; Mills 2012), both within individual companies and collectively (Geneva Association 2009). Think-tanks were established and climate related insurance products have been developed (Surminski et al. 2016). One group of experts looking at the role of insurance in climate change 10 years ago concluded that the challenge had to be tackled by private and public sectors in collaboration (Gurenko 2006).

However, ideas for employing the industry's ability to help avoid or minimize and, if necessary, compensate for uncertain costs in the future at scale, across national boundaries, and as part of a broader regime that seeks to maximize existing capacities and market mechanisms, seem to be lacking.

\section{Proposing a new type of climate change insurance}

This section describes polycentric governance for climate change insurance (PGCCI) in a regime that follows four rules:

(1) Fossil fuels are "insured";

(2) Products are labeled to denote whether their embodied energy was produced with noninsured fossil fuels or not (i.e. only with insured fossil fuels and/or renewable energy);

(3) The collected premiums are used to mitigate, adapt to climate change, and compensate for specified losses caused by climate change; and

(4) Producers of insured fossil fuels are protected against claims of liability for damages from climate change, unlike producers of non-insured fossil fuels. ${ }^{1}$

\footnotetext{
${ }^{1}$ It is up to courts to determine how to apply this rule and thus to contribute to and shape PGCCI. This is why we cannot call the proposed scheme liability insurance. Moreover, this rule does not address, nor preclude, the question of liability for non-insured fossil fuels produced in the past.
} 
Of all anthropogenic climate change, roughly three-quarters is caused by the consumption of fossil fuels. This human-induced climate change can be attributed to the oil, gas, and coal companies, according to the carbon content of the fuels they extract and sell (Heede 2014). This attribution to fossil fuel companies matters, because it allows the internalization of costs at the beginning of the causal chain. Indeed, the only practical way to charge polluters is for fossil fuel-extracting companies to pay a surcharge at the source (Marland et al. 2015).

That surcharge, proportional to the fuels' carbon content, can be passed on in the form of price increases for fossil fuels themselves, which eventually will result in price increases paid by consumers for final products. Applying the insurance concept, we propose that this surcharge is best thought of and explained as an insurance premium. Since the price increases are passed through, any consumer or company purchasing energy or goods produced with fossil fuels that were fully "insured", 2 will have contributed to insuring against the damages that the direct and indirect consumption of fossil fuels is likely to cause in the future.

While the proposal is unlike traditional insurance, the surcharge is called an insurance premium. Insurance companies are given a prominent role because the principles of insurance can be applied to key aspects of climate change, and because insurance companies have the capacity to administer large sums of money. The basic insurance principles we refer to are mainly precaution, risk assessment and risk sharing in combination:

- Precaution: Money is collected now in view of averting and compensating for future damage. ${ }^{3}$

- Risk assessment: The insurance industry is able to assess risks, ${ }^{4}$ calculate premiums and set ex-ante rules for the payments (averting and relieving disaster).

- Risk sharing: The number of payments into the insurance pool is significantly larger than the number of payments out, as in our proposal each purchase of insured fuel represents a payment into the insurance scheme.

However, since climate change as a phenomenon cannot be insured on account of its diffuseness and magnitude, insurance companies will only carry limited risks and will not be in competition with one another in the traditional way. The level of the premium will not be determined by individual companies independently.

Instead, a pool of participating insurers, working jointly with a regulatory body set-up by the UNFCCC is at the heart of the proposed scheme. The public-private oversight body will be responsible for setting and periodically reviewing key parameters, such as the height of the premiums and what fraction of the collected premiums go to mitigation, adaptation and compensation.

What level of insurance premium is feasible? For an initial calculation: the value of fossil fuels traded globally varies from year to year, but is around USD 5 trillion annually

\footnotetext{
${ }^{2}$ We use the term "insured" fossil fuels, energy, goods, or services to denote instances where at the beginning of the value chain the surcharge or premium was paid for all fossil fuels used. Such "insured" energy could also be mixed with energy from renewable sources.

${ }^{3}$ Carbon taxes, carbon credits or certificates, admittedly, have also precautionary elements, but in this proposal precaution is tackled head on. In case of taxes, be they Pigout taxes or dedicated taxes, their later use is at the discretion of governments with priorities which may change over the years. For more on precaution see, for example, Persson 2016.

${ }^{4}$ Not all climate change risks are amenable to quantitative assessment. But there are plenty of disaster scenarios which potentially can be insured, if the financing is taken care of (Surminski et al. 2016) - and with ongoing research their spectrum widens.
} 
(see Table 1). If premiums are set to reflect emissions' external cost and we assume a price of USD 25 per metric ton of $\mathrm{CO}_{2}$, a value that is in line with conservative estimates of external costs of $\mathrm{CO}_{2}$ emissions, ${ }^{5}$ and we further assume - for the sake of this calculation - that all fossil fuels are fully insured, the price increase would be on average $17 \%$. That is significantly less than price fluctuations due to political or economic shocks, for example. Prices of most final products would increase only by a fraction of the fuels' price increase. Nevertheless, since premiums would be set proportional to the fuels' impact on climate change, the resulting price increases would provide an incentive along the full value chain to reduce energy consumption or reduce the climate impact per unit of energy. There would be an effort to switch away from coal as a fossil fuel, since its climate impact - and therefore the premium paid per unit of energy - is far higher than for oil or gas.

How much financing would this generate and how will the funds be used? The number of USD 840 billion is a theoretical total under the above used assumptions of a price of USD 25 per metric ton of $\mathrm{CO}_{2}$ and all fossil fuels being fully insured. We should not expect full insurance coverage of fossil fuels, even in the long term, and insurance premiums themselves are expected to induce lower levels of fossil fuel consumption, especially of coal. On the other hand, the price set for a ton of $\mathrm{CO}_{2}$ may be increased beyond the USD 25 assumed here. For another initial calculation: if we assume insurance coverage of fossil fuels at $10 \%$ of 2013 levels for coal and $50 \%$ for both oil and gas, total premiums would amount to approximately USD 268 billion. After the insurance companies have been compensated for collecting and managing premiums ${ }^{6}$ (e.g. $6 \%$ of total funds) and funds have been set aside for external monitoring of value chains (e.g. $4 \%$ of total funds), $30 \%$ or USD 80 billion annually would be set aside each for mitigation, adaptation, and compensation. The exact allocations will have to be negotiated in detail and periodically reviewed by the public-private oversight body, which will also monitor the use of all funds on an ongoing basis.

The collection of premiums amounting to hundreds of billions of dollars requires financial management capacity that insurance companies have or are well placed to build up. In Fig. 1, we illustrate how we envision the flow of funds from fossil fuel companies to direct insurers to an insurance pool onward to mitigation and adaptation projects and instruments focused on adaptation and compensation.

For projects focused on mitigation and adaptation, insurance companies will transfer funds through the pool of insurers to existing institutions, including the Green Climate Fund. For adaptation and compensation, funds will be used to subsidize public authorities' or communities' purchases of insurance products that already exist and can be further developed, such as Cat Bonds, index-based insurance and other new innovative risk financing mechanisms (see, for example, Linnerooth-Bayer and Hochrainer-Stigler 2015). Insurance companies will be able to either use funds for subsidizing such insurance products directly, or pass the collected funds to the pool for allocating subsidies. The fact that funds would be used to subsidize instruments for adaptation and compensation, rather than outright compensation for damages from extreme weather events, reduces the need to precisely quantify the fraction of weather

\footnotetext{
${ }_{5}^{5}$ See, for example, Nordhaus 2015 , or estimates by the US EPA, online at http://www.epa.gov/climatechange/ EPAactivities/economics/scc.html, accessed 22 June 2015.

${ }^{6}$ This could include the following tasks: collect premiums; administer funds, incl. Contributing to critical database for labeling; participate in pool of insurers to set premiums and direct use of funds; develop innovative products for adaptation and compensation.
} 


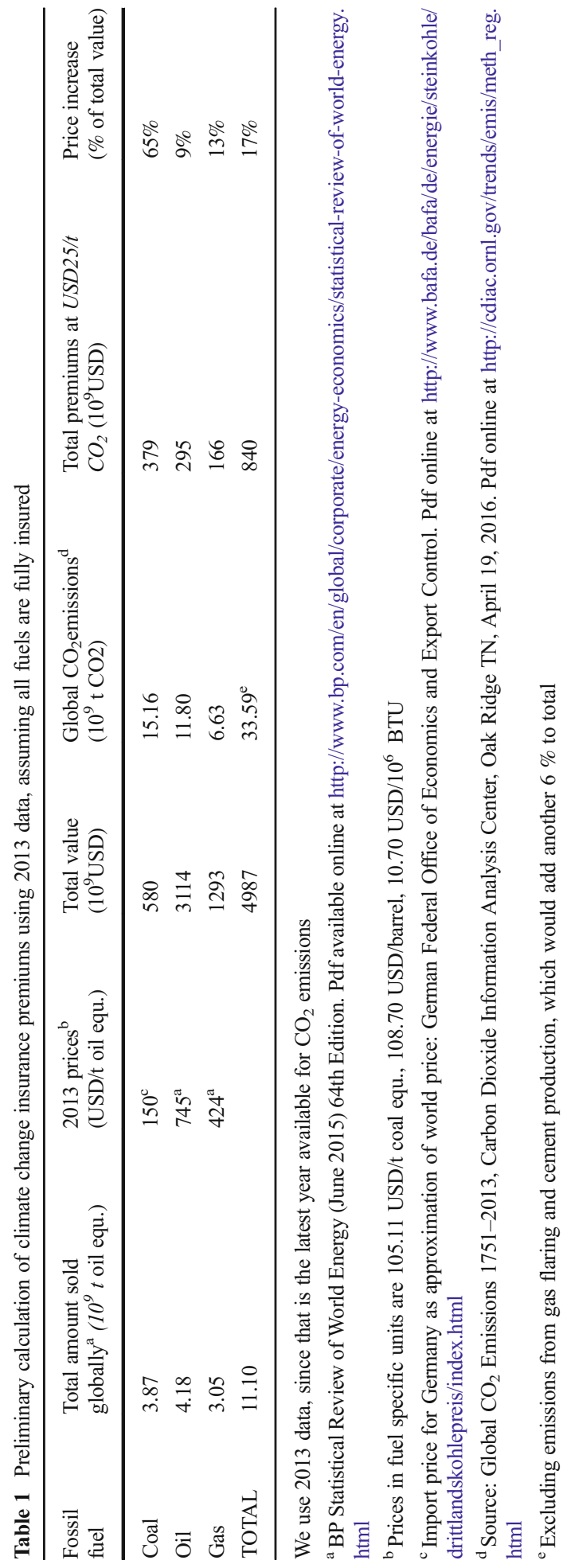


Fig. 1 Proposed flow of funds for climate change insurance

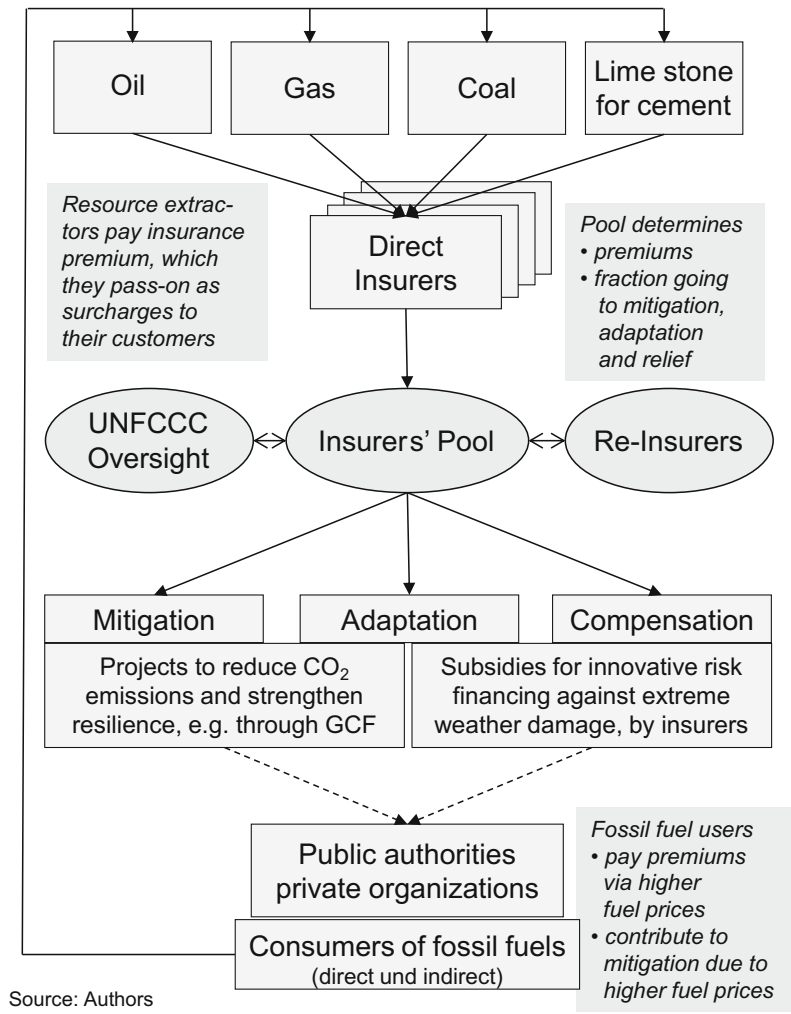

damage that is due to climate change. The level of subsidy can be set for each country; e.g. inversely proportional to the cumulative per-capita carbon footprint.

The complementary task to setting premiums and collecting them is establishing a mechanism for identifying insured vs. uninsured fossil fuels, and thereby being able to distinguish final goods as being produced with exclusively insured or renewable energy vs. final goods that are produced at least in part with noninsured fossil fuels. This is akin to labeling that is well known in other spheres, such as agricultural products that are "certified organic, as per USDA rules" or the efforts to introduce "fair trade" as a distinguishing label for goods from developing countries. The challenge of establishing such a mechanism is a formidable one, of course, not least because it will require ongoing monitoring and auditing of value chains, though resources will be made available from the collected premiums. In the above example, $4 \%$ of 268 would amount to more than USD 10 billion annually. Also here, there are actors who either already have or are well placed to build up the capacity to carry out such monitoring.

The compulsion for firms and consumers to switch toward goods and services that are fully "climate change insured and renewable" can build over time, as the labeling gains traction. For example, public administrations in selected countries may require all public contracts to be "insured", leading all providers that use energy from non-insured fossil fuels to be excluded. Similarly, international brands seeking to differentiate themselves among environmentally 
conscious consumers may choose to switch to fully climate change insured and renewable energy, which in turn would force all their suppliers along the value chain to switch to insured fuels as well. As an increasing number of decision makers, NGOs, and consumers demand that final products be free of noninsured fossil fuels, such action would likely spread.

The fact that the price increase comes in the form of an insurance premium (collected by insurance companies), rather than in the form of a carbon tax (collected by governments), matters for the proposal's likely acceptance and implementation. Consumers tend to accept price increases by suppliers in support of environmental goals quite readily, for example when used as cross-subsidies for renewable energy, especially if they occur gradually over time (Jacobs 2014). The contrast between insurance premiums and taxes also highlights the public trust required for the collection and management of such funds. Whereas multi-national insurance companies, as well as international auditors and NGOs, spend significant resources to ensure a uniform minimum standard of quality or fiduciary control across countries, the same cannot be said for governments. Across the globe, national administrations have vastly different capacity - and public trust in their ability - to save money for future, uncertain costs.

What about the fossil fuel companies? The World Energy Council called for a globally harmonized carbon price in a fairly recent statement (WEC 2015), thus implicitly agreeing with the notion that carbon should be priced in order to handle climate change. There is a growing discussion among NGOs, on behalf of victims of severe weather events, how to bring fossil fuel companies to court and sue for damages. ${ }^{7}$ If ceasing to sell non-insured fossil fuels eliminates the liability of fossil fuel producers (individually or collectively) for future sales, the fossil fuel industry overall may welcome the proposed insurance framework and the opportunity to become part of the solution, in terms of public relations as well as legally.

The proposal we are outlining here stands a better chance of being implemented than alternative approaches. Binding worldwide agreements, which are necessary to enforce treaties and have to be translated into national law in all countries are avoided. The contrast with a conceptually similar approach recently proposed by Nordhaus (2015) is useful to consider. Nordhaus argues in favor of a so-called Climate Club, a new type of free trade regime. National governments would be compelled to adopt strong climate policies, because failing to do so would result in the exclusion from the free trade area. Similar to our proposal, the Climate Club relies on the idea that it is possible to compel an increase in the price of carbon emissions (through national policies or through insurance premiums), if failing to do so results in a significant penalty (denial of access to the free trade regime or denial of access to markets that prohibit the use of non-insured fossil fuels). The key difference is that in the Climate Club the only relevant actors are national governments, whereas actions by other stakeholders are assumed away. Though Nordhaus bemoans the limitations of the Westphalian system that underlies international law, the Climate Club he proposes remains within these same limitations, unlike the polycentric governance proposed here. While the Climate Club paper represents a most welcome and indeed critical contribution, our proposal looks beyond national governments and suggests that at the international level, where there is no central authority, the responsibility to act has to be placed on many shoulders.

\footnotetext{
$\overline{7}$ Liability claims have been made, sometimes successfully, against government entities, deemed inactive in safeguarding injured parties against climate change (Lord et al. 2011). In 2015, Greenpeace and others helped claimants in the Philippines to make a liability claim against all major fossil fuel producers, which they call the “Carbon Majors” (Greenpeace 2015).
} 


\section{Mapping the institutional stakeholders}

We propose that without a global government, the responsibility and leverage for dealing with global commons, such as the global atmosphere, have to be shared among many actorsmaking it polycentric (Ostrom 2000, 2010; Sovacool 2011; Jordan et al. 2015). The principal actors are listed in Table 2. We have identified eight core clusters or "centers". Without any one of the eight centers the scheme would not work efficiently. Each center has its own functions and capabilities, but it also exercises influence on the other centers. The regime is not introduced through a global treaty or central authority, but by a combination of willingness and coercion of the centers and consumers to be part of the regime. While public authorities play a critical part, responsibility for enforcement does not rest solely with them. Instead, the proposed regime makes use of the fact that global markets and communications allow for aggregation of preferences within a polycentric regime that can impose discipline through denial of market access and can grow in strength and influence over time (Cole 2015).

Mechanisms need to be developed in more detail to introduce the proposed regime, for premium setting and collection, for labeling, and for how to use the premiums. This requires technical discussions with international organizations within the UN system, with the insurance industry, fossil fuel-companies, and well-established, international NGOs. On the basis of such preliminary mechanisms, piloting can be initiated with a small set of actors, representatives of the centers outlined above. The key element and advantage of PGCCI is that full agreement by everyone is not necessary to initiate the proposal.

\section{Conclusions and future research}

We believe that PGCCI points to a research agenda that will have to be pursued alongside its introduction and on a continuous basis. While some of the mechanisms, rules, and actors have to be defined for the pilot itself, making polycentric governance effective would require ongoing research to refine, revise, and adapt the regime's rules and practices.

We see five principal areas of research supporting the establishment and functioning of the regime:

- Synergies between our proposal and other ongoing efforts should be examined systematically;

- Business cases or relevant analyses of political economy are needed for all participating actors;

- Issues of accountability and compliance will need to be studied and monitored;

- Suitable investment and insurance mechanisms need to be developed further; and

- Continuous monitoring will be required to ensure that PGCCI implementation enables and demands constructive interactions to make the polycentric governance work properly.

From the start, synergies with on-going efforts to curb emissions, such as cap-and-trade schemes, the COP and climate relevant G7 initiatives, will need to be examined in-depth. The COP could, for example, boost the polycentric approach through a declaration that emissions from insured fossil fuels do not count against agreed limits. And PGCCI can be seen as a source of money for the G7-initiated GCF. On the other side of the spectrum, fuel subsidies continue to exist in many countries. While it is straightforward to determine that directly 


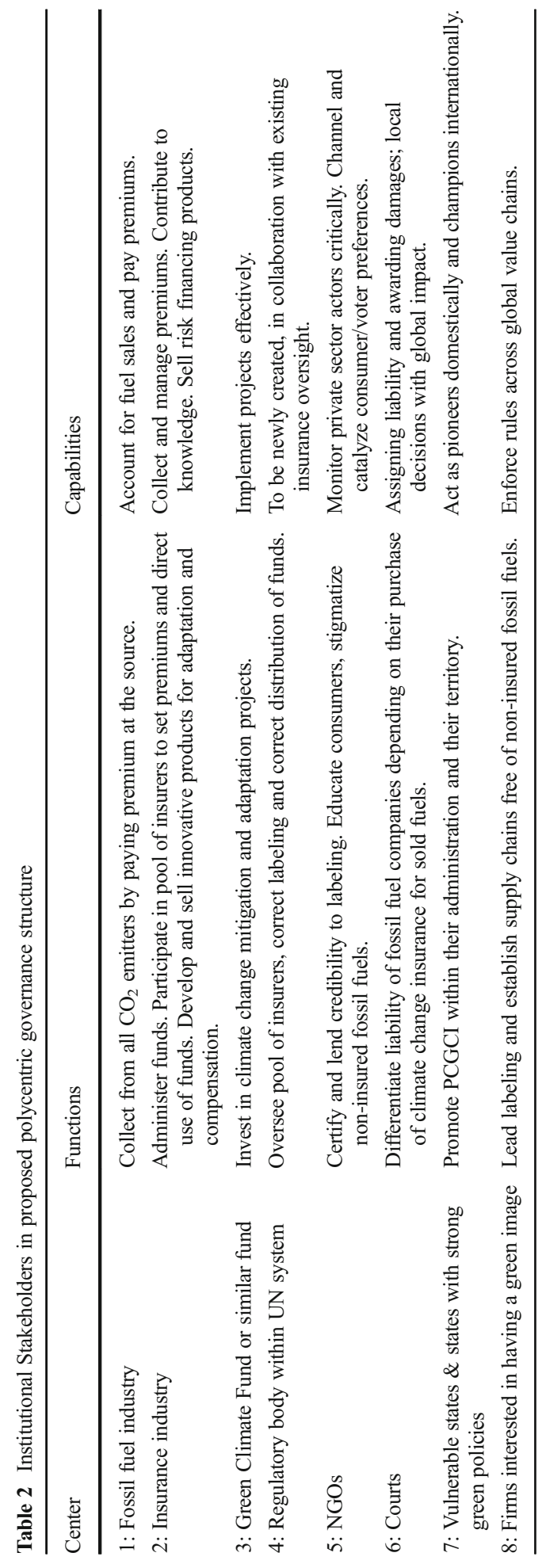


subsidized fuel will not be eligible to be insured, identifying and assessing more indirect forms of subsidies and how they should be treated under PGCCI will require careful study. It will also be interesting to track whether an expanding PGCCI regime has a significant impact on the prevalence of fuel subsidies.

The second principal area where more work is needed relates to the business cases for all the actors involved, as well as to the political economy of public entities and their regulatory functions. For the insurance industry, including re-insurers, it needs to be examined how our proposal ties in with other industry efforts aimed at addressing climate change. Will a role similar to the role US insurers play in flood insurance ${ }^{8}$ be attractive for individual insurance companies? Similarly, for fossil fuel suppliers the question of commercial viability and future business opportunities will need to be examined along with the dangers and/or opportunities to turn insured fuels from niche products into mass products. Well-established international NGOs will have to invest resources and reputation into making PGCCI work. Significant effort will be required to monitor compliance with labeling standards (i.e. making sure products that are labeled "insured" are not partly produced with cheaper non-insured energy). While funding will be set aside for monitoring compliance, the organizational resources required to carry out the work will grow rapidly as PGCCI expands. Finally, also national government and international organizations would have to signal the extent of their buy-in and active partnership.

The third research area relates to improving accountability and compliance under both our PGCCI scheme as well as other, related collective action problems. Issues of accountability and compliance remain one of the most critical issues in non-state initiatives responding to collective climate goals (Shelton 2000). The Green Climate Fund has for instance struggled to reach operationalization, and it requires less stringency than our insurance instrument would require (Fridahl and Linnér 2016). In the past, previously successful approaches have tended to work only when they actively share information, create strong networks of trust among participants, have aggressive sanctions for non-compliance, and also involve feedback from a diverse group of stakeholders, among other design principles. Some of these principles may apply to PGCCI, but future research needs to confirm or contextualize such principles.

The fourth research area relates to the further development of insurance instruments and suitable investment mechanisms. As PGCCI expands, so will the amount of collected premiums. It can be partly spent on subsidies, requiring innovative instruments, but will also require long-term investment strategies that align with climate change objectives. Though options for subsidizing innovative insurance products are being developed (see, for example, Munich Climate Insurance Initiative at www.climate-insurance.org) the funds that PGCCI may raise will require additional effort.

The fifth area where additional and ongoing research will be needed relates to polycentric governance, which shifts the burden for enforcement from governments onto multiple stakeholders, including international institutions, multinational companies, NGOs and consumers. It avoids the pitfall of many global agreements that rely on public enforcement alone, which tend to fail due to the large gap in capacity between governments of different countries. As PGCCI grows, and with it the number of organizations and amount of money involved, these relationships will become more challenging to manage effectively.

\footnotetext{
${ }^{8}$ In the US, the insurance industry has long avoided writing flood insurance, but they do participate in the National Flood Insurance Program (NFIP), but only to collect premiums, pay claims, and provide some services, but all the financial risk is passed on to the Federal Government (Anderson 2015).
} 
In sum, the research across these five principal areas can be started now and continue in parallel to piloting, as it becomes a continual corrective to implementation.

We suggest time has come to internalize the costs associated with climate change into a form of insurance. Not only can this complement ongoing policies aimed at mitigation and adaption, especially by funding them, it also distributes responsibility for climate change more directly among the consumers and companies causing it.

Open Access This article is distributed under the terms of the Creative Commons Attribution 4.0 International License (http://creativecommons.org/licenses/by/4.0/), which permits unrestricted use, distribution, and reproduction in any medium, provided you give appropriate credit to the original author(s) and the source, provide a link to the Creative Commons license, and indicate if changes were made.

\section{References}

Allen M (2003) Liability for climate change. Nature 421:891-892

Anderson D (2015) Private communication (Dan Anderson is Professor Emeritus, University of Wisconsin) Chichilnisky G, Heal GM (1993) Global environmental risk. J Econ Perspect 7(4):64-86

Cole DH (2015) Advantages of a polycentric approach to climate change policy. Nat Clim Chang 5:114-118

Fridahl M, Linnér, BO (2016) Perspectives on the Green Climate Fund: Possible compromises on capitalization and balanced allocation. Climate and Development.

Geneva Association (2009) The insurance industry and climate change - Contribution to the global debate. Published online July www.genevaassociation.org

Greenpeace (2015) Petition to the Commission on Human Rights of the Philippines Requesting for Investigation of the Responsibility of the Carbon Majors for Human Rights Violations or Threats of Violations Resulting from the Impacts of Climate Change http:/www.greenpeace.org/seasia/ph/PageFiles/105904/ClimateChange-and-Human-Rights-Complaint.pdf

Gurenko EN (2006) Executive summary of special issue: climate change and insurance. Clim Pol 6(6):600-606

Heede R (2014) Tracing anthropogenic carbon dioxide and methane emissions to fossil fuel and cement producers, 1854-2010. Clim Change 122(1-2):229-241

Jacobs D (2014) Policy invention as evolutionary tinkering and codification: the emergence of feed-in tariffs for renewable electricity. Environmental Politics 23(5):755-777

Jordan AJ, Huitema D, Hildén M, van Asselt H, Rayner TJ, Schoenefeld JJ, Tosun J, Forster J, Boasson EJ (2015) Emergence of polycentric climate governance and its future prospects. Nat Clim Chang 5:977-982

Linnerooth-Bayer J, Hochrainer-Stigler S (2015) Financial instruments for disaster risk management and climate change adaptation. Clim Chang 133:85-100

Lord R, Goldberg S, Rajamani L, Brunnee J (2011) Climate Change Liability: Transnational law and practice. Cambridge University Press ISBN 9781107017603

Marland G, Kowalczyk T, Marland E (2015) Carbon accounting: issues of scale. J Ind Ecol 19(1):7-9

Mills E (2005) Insurance in a Climate of change. Science 309:1040-1044

Mills E (2012) Climate change: the greening of insurance. Science 338:1424-1425

Munich Re (1973) Flood inundation. Munich Reinsurance Company, Munich

Nordhaus W (2015) Climate clubs: overcoming free-riding in international climate policy. Am Econ Rev 105(4): $1339-1370$

Nuzzo R (2005) Profile of Stephen H. Schneider. PNAS 102(44):15725-15727

Ostrom E (2000) Collective Action and the Evolution of Social Norms. J Econ Perspect 14(3):137-158

Ostrom E (2010) Polycentric Systems for Coping with collective action and global environmental change. Glob Environ Chang 20:550-557

Persson E (2016) What are the core ideas behind the precautionary principle? Sci Total Environ 557-558:134141

Schneider SH, Kuntz-Duriseti K (2002) Uncertainty and Climate Change Policy. In: Schneider SH, Rosencranz A, Niles JO (eds) Climate Change Policy: A Survey. Island Press, Washington D.C.

Shelton D (Ed.) (2000) Commitment and Compliance; The Role of Non-Binding Norms in International Law. Oxford University Press.

Shiller RJ (2014) Buying Insurance Against Climate Change. The Upshot: Economic View in the NYTimes of May 24 
Sovacool BK (2011) An international comparison of four polycentric approaches to climate and energy governance. Energy Policy 39(6):3832-3844

Surminski S, Bouwer, LM, Linnerooth-Bayer J (2016) How insurance can support climate resilience. Nat Clim Chang, Vol 6, www.nature.com/natureclimatechange

UNFCCC, COP19 (2013) Executive Committee of the Warsaw International Mechanism for Loss and Damage. http:/unfccc.int/adaptation/groups_committees/loss_and_damage_executive_committee/items/7543.php

UNFCCC, COP21 (2015) Paris Agreement. https://unfccc.int/resource/docs/2015/cop21/eng/109r01.pdf.

World Energy Council (2015) World Energy Trilemma: Priority actions on climate change and how to balance the trilemma. London, ISBN: 9780946121403 